\title{
EFEITOS DOS ESTEROIDES ANDROGÊNICOS ANABÓLICOS EM ADOLESCENTES PRATICANTES DE MUSCULAÇÃO: IMPLICAÇÕES À SAÚDE ${ }^{*_{1}}$
}

\author{
Janaina Brandão Neves ${ }^{2}$ \\ Evandro Salvador Alves de Oliveira ${ }^{3}$ \\ Lorena Cristina Curado Lopes ${ }^{4}$
}

\section{Introdução}

Este capítulo propõe uma discussão que entrelaça o tema esteroides androgênicos anabólicos (EAA) em adolescentes praticantes de musculação. Abordar esse tema é tocar em um tipo de assunto que envolve questões bastante polêmicas. Reconhecendo isso, destacamos que o objetivo geral deste capítulo é analisar os efeitos do uso de EAA em adolescentes praticantes de musculação bem como compreender os fatores associados ao uso destas substâncias.

Dentre as inúmeras possibilidades de investigar a temática relacionada aos assuntos polêmicos que envolvem a utilização de substâncias ilícitas no universo da atividade física, este trabalho tem como mote principal analisar os efeitos que acontecem com adolescentes que praticam a musculação e utilizam esteroides androgênicos anabólicos (EAA). De acordo com Silva, Danielski e Czepielewski (SILVA, CZEPIELEWSKI, 2002), os EAA são produtos feitos a partir da testosterona que promovem um efeito anabólico no tecido muscular com contribuições significativas no aumento da força.

${ }^{*} 10.29388 / 978-65-86678-46-8-0-f .167-180$

1 O presente capítulo é fruto de um trabalho de conclusão de curso (Bacharel em Educação Física - UNIFIMES, GO) orientado pelo Prof. Dr. Evandro Salvador Alves de Oliveira.

${ }^{2}$ Graduada em Educação Física pela UNIFIMES. Graduada em Nutrição pela FAMP. E-mail: janainabrandao nutri@hotmail.com

${ }^{3}$ Doutor em Estudos da Criança pela Universidade do Minho. Doutor em Educação pela Universidade de Uberaba. Mestre em Educação pela Universidade Federal de Mato Grosso. Graduado em Educação Física pelo Centro Universitário de Santa Fé do Sul. Pesquisador e Professor efetivo do Centro Universitário de Mineiros. E-mail: evandro@,unifimes.edu.br

${ }^{4}$ Docente efetiva do Centro Universitário de Mineiros - UNIFIMES. Doutoranda em Ciências da Saúde pela UFG. E-mail: lorena.lopes@unifimes.edu.br 
No campo da Educação Física e da saúde coletiva, entendemos que discutir esse assunto é relevante, por vezes polêmico, sobretudo por compreendermos que no meio profissional um dos grandes públicos que estes profissionais lidam cotidianamente são os adolescentes. Este grupo encontra-se vulnerável frente as informações proporcionadas pela globalização, e a necessidade de se encaixar dentro dos padrões impostos socialmente. Contudo, as análises aqui presentes são interpretadas à luz de profissionais da área da saúde, que tem se aprofundado especialmente sobre questões que dizem respeito ao campo da Educação Física.

Nesta pesquisa qualitativa procuramos direcionar as análises com base nas questões que mais se destacaram nas produções bibliográficas encontradas ${ }^{5}$. Temos o pressuposto de que na infância inicia a construção de um processo que toma o corpo como importante "joia" lapidada pela cultura humana que envolve a valorização pelo físico bonito, forte, visível e cobiçado. Ou seja, crianças e jovens aprendem a valorizar o corpo magro, esbelto, sarado e "malhado" desde muito pequenas.

Os estudos de Oliveira (2014), sobre as culturas (lúdicas) infantis na era da cultura midiática, bem como as análises críticas de Salgado e Ferrarini (2016), apontam que as crianças aprendem e começam a idealizar um corpo dentro dos padrões sociais desde muito pequenas. Ou seja, aquele corpo que a sociedade tem modelado, que não pode ser acima "do peso", nem "baixo", nem "alto demais", e que os músculos precisam aparecer, são observados e idealizados por jovens, adolescentes, inclusive pelas crianças. Se trata de uma questão cultural que não podemos deixar de levar em consideração.

As pesquisas com as quais nos deparamos também têm apontado elevação no uso desordenado de EAA por adolescentes, fisiculturistas e atletas, e no caso do Brasil a quantidade de trabalhos científicos sobre essa temática ainda é muito escassa (IRIART, ANDRADE, 2002).

Um grupo bastante afetado pelo consumo indiscriminado de EAA são os adolescentes (MARTINS et al., 2005). Alguns achados científicos sobre os adolescentes mostram um frequente e rotineiro aumento do consumo de anabolizantes, para uma finalidade não de competição, mas, sim, para alcançar o corpo almejado pela sociedade, idealizado como "belo" ou "ideal". Essa visão está cada vez mais está sendo estimulada pela supervalorização do corpo social, por um sistema capital

\footnotetext{
${ }^{5}$ Embora o estudo tenha o foco de discutir as produções bibliográficas publicadas nos últimos dez anos, não deixaremos de citar alguns trabalhos anteriores a essa data. Isto ocorre em razão da pertinência dos assuntos tratados, uma vez que consideramos importante trazer determinadas discussões e conceitos.
} 
imediatista e pós-industrial difundido (OLIVEIRA, 2014). Assim, vemos que o público de adolescentes se preocupa com o encurtamento desse caminho, principalmente por esses indivíduos recorrerem a utilização dessas substâncias. Por isso, o objetivo do presente estudo é analisar os efeitos dos EAA em adolescentes praticantes de musculação bem como compreender os fatores associados ao uso destas substâncias.

\section{Metodologia}

Quanto à metodologia, destacamos que este trabalho foi alicerçado nos pressupostos do método qualitativo, sendo este uma revisão sistemática narrativa, inspirado no estado do conhecimento, que não teve como foco ater-se em questões quantitativas. Pelo contrário, as análises voltam-se aos aspectos qualitativos (implicações) que envolvem o objeto em questão.

Foram pesquisados artigos nas bases de dados: Scielo (Scientific Electronic Library Online); LILACS (Literatura Latino-americana e do Caribe em Ciências da Saúde) e no banco de Teses e Dissertações da CAPES (Coordenação de Aperfeiçoamento de Pessoal de Nível Superior), por meio da Biblioteca brasileira digital de teses e dissertações (BDTD). Foram utilizados os seguintes descritores: Adolescentes e Musculação, Adolescentes e Anabolizantes, Musculação e Anabolizantes. Como critérios de inclusão, foram selecionadas produções em língua portuguesa relacionadas com a temática, preferencialmente dentro do recorte temporal de 2010 a 2019, para compor a análise dos dados coletados.

\section{Musculação durante a adolescência e a busca do corpo perfeito}

A musculação, que é também reconhecida como treinamento de força ou contra resistência, até mesmo como treinamento com pesos, transformou-se em uma das modalidades de exercício físico mais populares da contemporaneidade (FLECK; KRAEMER, 2017). Esta modalidade tem sido procurada por públicos distintos que buscam variados objetivos como aumento da força muscular, potência, melhorias no desempenho em modalidades esportivas, manutenção da saúde, e uma considerável parcela que visa melhorias em questões relacionadas à estética corporal (KRAEMER; RATAMESS, 2004). 
Dentre os adolescentes, é observado aumento pela procura da musculação. Tal fato é reflexo do crescimento no número de academias nas últimas décadas, bem como da ampla popularização do conhecimento sobre os benefícios desta modalidade (AZEVEDO JUNIOR; ARAÚJO; PEREIRA, 2006). Além disso, a procura da musculação entre os adolescentes, especialmente do sexo masculino, muitas vezes está relacionada com questões de busca de uma imagem corporal que seja aceita pelos padrões de beleza.

A musculação colabora para a construção do padrão da beleza masculina, baseada nos ideais de masculinidade, como a força e o tamanho dos músculos, que são sinônimos de virilidade e que dão prestígio aos sujeitos. Dessa maneira, a conformação da masculinidade e beleza a ela relacionada, é obtida através da musculação, como obtenção de braços fortes e delineados, peitoral proeminente, ombros largos, pernas grossas, postura altiva e abdômen definido (TRABBOLD, 2008).

Provavelmente os sujeitos que buscam o corpo perfeito muitas vezes, percorrem caminhos (não saudáveis) mais curtos em virtude da "necessidade" de se adequar aos padrões sociais, construídos historicamente. Ou até mesmo por problemas relacionados com a própria visão do corpo que indivíduos possuem. São as possíveis frustrações que seres humanos enfrentam, inclusive os adolescentes, que provavelmente os impulsionam a buscar a rápida e sólida definição muscular. Ao procurar outras alternativas para alcançar o corpo "ideal", recorrem aos recursos farmacológicos, como os EAA.

A utilização dos EAA cresce em meio aos jovens praticantes de atividade física, em especial aqueles que buscam o corpo bonito e aperfeiçoamento da performance esportiva, sujeitando aos riscos clínicos dessa situação. Por exemplo, toxidade hepática, disfunções renais, alterações no perfil lipídico, complicações cardiovasculares (NIESCHLAG ; VORONA, 2015).

Do ponto de vista de desenvolvimento, Cunningham e colaboradores (Cunningham; McGinnis, 2013) identificaram que o abuso de EAA durante a adolescência, um período significativo de organização cerebral, altera o padrão normal de desenvolvimento cerebral, bem como a função dos neurotransmissores, que podem resultar em uma maior vulnerabilidade a distúrbios psicopatológicos e aumento da agressividade. Adicionalmente, nos adolescentes, o uso de EAA causam uma aceleração da maturação óssea, que leva ao fechamento do epifisário precocemente retardando assim o crescimento (NIESCHLAG; VORONA, 2015). 
Em conjunto todas estas alterações sistêmicas induzidas pelo abuso de EAA aumentam significativamente o risco de mortalidade. Em um estudo realizado entre 2006 e 2018 com 545 indivíduos do sexo masculino que utilizavam EAA, foi evidenciado que o risco de mortalidade é três vezes superior naqueles que fazem uso destas substâncias quando comparados com indivíduos que não fazem o uso destas substâncias (HORWITZ, ANDERSEN; DALHOFF, 2019).

\section{Tipos de esteroides anabólicos}

Durante as buscas sobre os principais tipos de esteroides encontramos estudos que mencionam determinadas substâncias, como as pesquisas de Iriart e Andrade (2002) e Hartgens e Kuipers (1985). Os teóricos destacam haver várias substâncias, mais de 25 exemplos, incluindo suplementos vitamínicos veterinários, droga antiparasitária, entre outros, destacando o nome das 7 substâncias mais utilizadas.

O estudo de Iriart e Andrade (2002), realizado com jovens atletas, evidenciou a utilização de várias substâncias, como Durasteron (testosterona), Stradon P (testosterona + estradiol), Deca-durabolin (nandrolona), Uniciclo (algestone + estradiol), Premarim (estrógenos), suplementos vitamínicos veterinários com vitaminas A, D e E, Potenai (vitamina B) e medicamento antiparasitário (ivermectina), drogas de fácil acessibilidade. Porém com altas chances de falsificações colocando ainda mais a situação de saúde dos usuários em risco.

Tendo em vista as substâncias utilizadas pelos indivíduos, entendemos que as implicações destas podem variar. Por um lado, o organismo é capaz de responder positivamente a respeito dos exercícios e estímulos provocados no corpo, causando mais força e acelerando o processo de ganho de massa muscular magra. Por outro lado, existem efeitos colaterais que de certa maneira implicam na diminuição ou atrofia do volume testicular (no homem), redução da contagem de espermatozoides, problemas relacionados à fertilidade, calvície, hipertrofia da próstata e ginecomastia; na mulher, hirsutismo, alteração do padrão do clico menstrual e atrofia das mamas. Já nos adolescentes, os problemas são relacionados a maturação esquelética precoce, baixa estatura e alteração do período de puberdade (MACHADO; RIBEIRO, 2004).

A respeito do componente farmacológico decanoato de nandrolona, conhecido como (Deca-durabolin), é comum em uso veterinário para supressão de medula óssea, em tratamento quimioterápico (PEREZ 
et al., 2005). Essa substância, decanoato de nandrolona, é comumente utilizada em pessoas que praticam esportes e buscam um rápido efeito na hipertrofia muscular e na melhora do desempenho. Porém, o estudo in vitro de Ribeiro et al. (RIBEIRO et al., 2014) mostrou que essa substância não foi capaz atuar no processo de reparação muscular.

\section{A adolescência como a fase de risco ao uso de EAA}

A adolescência se trata de um período do desenvolvimento humano onde ocorrem diversas mudanças, conforme descrevem Romer e Hensses (2007). Ela se caracteriza, dizem os autores, por um processo de maturidade crescente, que envolve uma série de transformações físicas, emocionais, cognitivas e sociais, podendo fazer com que o jovem, de forma errônea, não concebe a devida importância.

$\mathrm{Na}$ atualidade, a adolescência é compreendida como um período de suma importância nos parâmetros de desenvolvimento e crescimento humano, fase na qual se inicia a puberdade com visíveis alterações físicas e biológicas. É a partir dessa fase que inicia o momento de vivenciar suas próprias experiências sobre o mundo, tornando-a uma fase de comportamento de risco elevado (Romer e Hennessy, 2007). Nesse cenário, segundo os autores, o corpo em questões físicas assume proporção de grande importância na vida do jovem.

Entendemos, pois, que corpo, adolescência e mente são dimensões indissociáveis e as profundas transformações físicas que os jovens vivenciam são resultados da formação da identidade psicológica e social que o adolescente apresenta. É de conhecimento que a preocupação com a estética corporal, melhores condições físicas e desempenho, vem se multiplicando ao longo dos tempos. Nas mais variadas culturas, no decorrer dos anos, os corpos tornaram-se objeto de culto e adoração. A superestimação da imagem corporal é a principal causa pelo acréscimo de distúrbios relacionados à própria imagem. Prova disso é o aumento exorbitante de números de casos como a bulimia, da anorexia, da vigorexia e o número de cirurgias plásticas (OLIVEIRA; CAVALCANTE NETO, 2018).

Sendo assim, jovens buscam atitudes inadequadas para conseguir o peso desejado, e por isso adotam práticas arriscadas, desencadeando transtornos alimentares, além de uso de diuréticos, baixa na ingestão calórica, autoindução de vômitos e também compulsão por exercício físico. Práticas de comportamentos inadequados por consequência de insatisfa- 
ção da imagem corporal, podem acarretar transtornos psicológicos, prejuízos no estado nutricional, se comparados aos adolescentes satisfeitos com sua imagem corporal (OLIVEIRA, 2018).

Por considerarmos que esse fenômeno que envolve adolescência e corpo se trata de um aspecto cultural, reconhecemos que é nessa fase da vida que meninos e meninas começam a explorar o uso de substâncias EAA para alcançar o corpo esbelto, forte e cobiçado (TRABBOLD, 2008). A esse respeito, procuraremos na próxima subseção mostrar os resultados mais expressivos sobre as produções teóricas encontradas para análise.

\section{O que revelam as produções científicas nos últimos anos sobre a temática abordada?}

Aqui apresentamos e discutimos a produção sobre a temática que envolve o uso de EAA e seus efeitos no público adolescente nos últimos anos. Por meio dos descritores utilizados para fazer as buscas, encontramos uma quantidade de produções relevantes.

Ainda que tivéssemos encontrado uma quantidade elevada de produções durante as buscas (totalizando 110 trabalhos), foram selecionados apenas os trabalhos que possuem relação direta com o tema musculação e anabolizantes na fase da adolescência.

Quadro 1. Relação de trabalhos encontrados em língua portuguesa

Bases de Pesquisa

Descritores (palavras-chave)

Adolescente e musculação

Artigos

(Scielo e Lilacs)

Teses

Dissertações

Total
Adolescente e Musculação

Adolescente e Anabolizante

Musculação e Anabolizante
Número de resultados encontrados

Scielo 02

Lilacs $\quad 38$

Scielo $\quad 04$

Lilacs 23

Scielo 05

Lilacs $\quad 16$

09 
Fonte: Elaborado pelos autores (2019)

Tal como mostra a Tabela 1, foram encontrados 110 trabalhos científicos, entre teses, dissertações e artigos completos. Desses trabalhos, foram selecionados para este estudo um total de 17 produções bibliográficas. Os critérios utilizados para seleção, ao ler os resumos, foram: produções que se encontravam em língua portuguesa; que apresentasse método de pesquisa qualitativo ou quantitativo; e que fosse sobre o uso de EAA com o público adolescente.

Dos artigos selecionados, 8 provem das bases de dados Lilacs e Scielo. Já no banco de dados da BDTD selecionamos 9 trabalhos, entre teses e dissertações.

Para iniciar o debate, trazemos aqui um conjunto de subsídios sobre as conclusões textuais dos estudos selecionados, fazendo inferência aos achados mais pertinentes. Começamos a discussão com os dados publicados por Medeiros (2012) que analisou em seu trabalho questão relacionada à cirurgia para ginecomastia. Para ele, os 32 pacientes do sexo masculino, entre eles adolescentes, tiveram ginecomastia, aumento benigno do tecido glandular da mama masculina provocada pela alteração das concentrações de estrógeno. A principal causa desta alteração foi idiopática, sem causa específica, seguida pelo uso de esteroides anabolizantes, fazendo assim uma correlação da utilização de esteroides anabolizantes com o crescimento da mama em pessoas do sexo masculino.

No estudo qualitativo de Carregosa e Faro (2016), os autores analisam o entendimento dos adolescentes sobre os conceitos, benefícios e prejuízos da utilização dos anabolizantes. A pesquisa avaliou 508 adolescentes, meninos e meninas, e dessa amostra $27,4 \%$ praticavam musculação. Os relatos dos adolescentes revelam que eles entendem haver uma preocupação sobre o corpo e aparência física, enquanto a compreensão sobre o conceito de saúde se encontra em um contexto subentendido pelo discurso de uma "aparência saudável". Os autores ainda reforçam aspectos sobre a divergência entre os ganhos e as perdas vividas pelos adolescentes quanto à utilização dos EAA. Nem todos adolescentes são desinformados, atestam Carregosa e Faro (Carregosa e Faro, 2016), pois muitos deles buscam entender sabiamente essa temática - o que de certa maneira nos preocupa em relação aos perigos que existem.

No estudo de Dartora, Wartchow e Rodrigue-Acelas (2014), encontramos aspectos sobre o uso abusivo de esteroides como um problema de saúde pública. Neste trabalho os autores elaboram uma revisão sobre a aplicação dos anabolizantes e seus problemas associados aos jo- 
vens esportistas. Como resultados os autores discutem que entre os maiores utilizadores de EAA estão os adolescentes que possuem a ideia de manter a imagem corporal baseada em estereótipos construídos pela sociedade. Se não fosse por meio dessa construção histórica, de valorização do corpo sarado, o consumo dos EAA seria ineficaz.

$\mathrm{Na}$ pesquisa de Schwingel e colaboradores (2012) são discutidas questões sobre as alterações hepáticas em usuários de esteroides anabolizantes, especialmente doenças esteatose hepática não alcoólica. De acordo com o estudo, os entrevistados relataram que o consumo dessas substâncias serviu para melhorar a massa muscular para os padrões estéticos, onde $60 \%$ da amostra informou que utilizaram para hipertrofia. O estudo apresenta, ainda, aspectos sobre os riscos da utilização do uso indis criminado dessas substâncias, alteração no metabolismo do colesterol e das lipoproteínas, além das doenças crônicas não transmissíveis.

Um trabalho realizado na Bahia, com 43 participantes, por meio de entrevistas, buscou avaliar a motivação pela utilização de anabolizantes. Esse estudo foi de caráter antropológico do tipo etnográfico e mostrou que em sua maioria a utilização dessas substâncias foi entre pessoas de classe média, motivadas sobretudo, por razões estéticas. Dentre os motivos que levaram ao uso, foi relatada a insatisfação com próprio corpo em comparação ao que a sociedade preconiza como "corpo belo", ligado a pressa sobre o resultado em obter esse padrão. Buscando, assim, rapidez nos resultados, colocando a saúde em risco (Iriart, Chaves e Orleans, De, 2009).

Nesse mesmo sentido, a pesquisa recente de Oliveira e Cavalcante-Neto (2018) revelam que essa busca pelo corpo perfeito é um dos motivos mais utilizados para justificar o consumo de EAA em praticantes de musculação, ainda que os usuários saibam dos riscos e efeitos colaterais. $\mathrm{O}$ estudo desses autores mostrou que quanto maior for o tempo da prática da musculação, maior é a chance de uso dos esteroides anabolizantes.

Outro motivo para o consumo de EAA seria os efeitos anabólicos sobre a massa muscular. No trabalho de Brito e Faro (2017) ficou evidenciado que o uso destas substâncias pode levar à dependência, distorções na imagem corporal, transtornos de imagens caracterizados por preocupação excessiva com o corpo, como o caso da vigorexia - condição na qual o indivíduo considera-se pequeno e fraco, mesmo apresentando grande quantidade de massa muscular. 
Todas essas dimensões da utilização de EAA estão ligadas a valorização do corpo. Jovens em busca do corpo perfeito, custe o que custar, se submetem ao consumo de substâncias que agridem a saúde. Esse discurso sobre o corpo em sua maioria é colocado por adolescentes. Um estudo avaliou 3150 adolescentes do sexo masculino que praticavam musculação. Os autores observaram que os adolescentes que tinham a maior quantidade de massa magra estavam mais satisfeitos com o seu corpo, e os adolescentes que praticavam musculação nas academias buscavam essa mesma finalidade, aumento de massa magra. Porém, os mesmos não tinham orientações de profissionais, aumentando assim o risco de utilização EAA (OLIVEIRA; CAVALCANTE NETO, 2018),

Nessa perspectiva, verificamos que Trabbold (2010) buscou compreender os sentidos atribuídos ao corpo por adolescentes que praticavam exercício físico em acadêmicas no estado de Minas Gerais, bem como as motivações para essa prática. Como desfecho a autora expôs as justificativas e as convicções estéticas, fazendo com que esses padrões possam ser correlacionados à utilização do uso de anabolizantes para obtenção de ganho de massa muscular de forma rápida. Assim, constatamos que a hipertrofia muscular se mostra como o maior objetivo perseguido pelos jovens que utilizam recursos farmacológicos.

Sob outro aspecto, uma pesquisa (SILVA, 2012) investigou a utilização frequente de EAA em frequentadores de academias de ginástica em João Pessoa. Seu estudo avaliou o medo e a relação de confiança na utilização dessas substâncias. Destaca o autor que essas questões corporais crescem junto com a insatisfação das pessoas que não aceitam seus corpos. O estudo (SILVA, 2012) conclui que os usuários de EAA confiam em seu efeito anabólico e também que esses usuários relatam a condenação dos EAA pelo sistema médico. No que diz respeito à utilização dessas substâncias para fins estéticos, grande parte do público considerou os EAA como produto desenvolvido para fins anabólicos e não como medicamentos.

Para finalizar as análises e discussões trazemos as considerações de Machado (2015), principalmente pela análise que faz com o campo da Educação Física. O autor faz inferências à questão das mídias e legislação sobre o uso de EAA com adolescentes praticantes de atividade física, tecendo críticas sobre a elaboração e a distribuição desse material por alunos da graduação em Educação Física. Dentro da Educação Física Machado (MACHADO, 2015) distingue perfis de estudantes, como exemplo aqueles que ingressam no curso com o propósito de entenderem so- 
bre a utilização dos anabolizantes e acabam se frustrando, pois esse assunto é pouco trabalhado dentro do curso e também por ser visto como tabu.

Desse modo, defendemos a ideia que os profissionais de saúde, especialmente os de Educação Física que lidam diretamente com estes adolescentes e são vistos como modelos de saúde, devem ter muita ética e responsabilidade ao lidar com o tema EAA, conhecendo os riscos do uso abusivo destas substâncias, ciente dos perigos e da ilegalidade da prescrição, e conscientes de que o uso terapêutico EAA para tratamento de condições clínicas deve ser indicado e acompanhado exclusivamente por médicos especialistas. Dessa forma, contribuímos para o fortalecimento da Educação Física, como uma ciência sólida e ética que busca promover e zelar pela saúde do indivíduo dentro de suas atribuições legais.

\section{Considerações finais}

O material analisado na pesquisa permite entender que os EAA estão sendo amplamente utilizados pelos adolescentes. Os estudos científicos analisados permitiram constatar, também, os seguintes aspectos: que muitos indivíduos se submetem à utilização dos EAA, uma vez que as questões psicossociais relacionadas ao corpo sobrepõem as questões do risco à saúde; os reais efeitos dos EAA são, muitas vezes, desconhecidos, principalmente pelas dificuldades éticas de realizar ensaios clínicos bem desenhados para mensurar os riscos do uso dos EAA. Contudo, a literatura até aqui é clara em mostrar associação entre o uso destas substâncias e piora nos desfechos de saúde.

Finalmente, concluímos que os trabalhos avaliados mostram uma preocupante condição relacionada ao uso precoce de substâncias ilícitas e que levam a grandes prejuízos na saúde. Destacamos que é de suma importância que os profissionais de saúde, especialmente os de Educação Física, adotem uma postura educativa sobre os riscos do uso em adolescentes e busquem uma prática profissional reflexiva acerca da influência negativa dos padrões de beleza sobre a saúde.

\section{Referências}


AZEVEDO JUNIOR, M. R. DE; ARAÚJO, C. L. P.; PEREIRA, F. M. Atividades físicas e esportivas na adolescência: mudanças de preferências ao longo das últimas décadas. Rev. bras. educ. fís. esp, p. 51-58, 2006.

BRITO, A. DE; FARO, A. Meanings of Anabolic-Androgenic Steroids: a Shock Between Desire and Risk. Psicologia, Saúde \& Doença, v. 18, n. 1, p. 102-114, 2017.

CARREGOSA, M. S.; FARO, A. O Significado dos Anabolizantes para os Adolescentes. Temas em Psicologia, v. 24, n. 2, p. 519-532, 2016.

CUNNINGHAM, R. L.; LUMIA, A. R.; MCGINNIS, M. Y. Androgenic anabolic steroid exposure during adolescence: Ramifications for brain development and behavior. Horm Behav.2, v. 64, n. 2, p. 350-356, 2013.

DARTORA, W. J.; WARTCHOW, K. M.; ACELAS, A. L. R. O Uso Abusivo De Esteroides Anabolizantes Como Um Problema De Saúde Pública. Revista CUIDARTE, v. 5, n. 2, p. 564-568, 2014.

FLECK, STEVEN J.; KRAEMER, W. J. . Fundamentos do Treinamento de Força Muscular. 4. ed. [s.l.] Artmed, 2017.

HORWITZ, H.; ANDERSEN, J. T.; DALHOFF, K. P. Health consequences of androgenic anabolic steroid use. Journal of Internal Medicine, v. 285, n. 3, p. 333-340, 2019.

IRIART, J. A. B.; ANDRADE, T. M. DE. Musculação, uso de esteróides anabolizantes e percepção de risco entre jovens fisiculturistas de um bairro popular de Salvador, Bahia, Brasil. Cadernos de Saúde Pública, v. 18, n. 5, p. 13791387, 2002.

IRIART, J. A. B.; CHAVES, J. C.; ORLEANS, R. G. DE. Culto ao corpo e uso de anabolizantes entre praticantes de musculação. Cadernos de Saúde Pública, v. 25, n. 4, p. 773-782, 2009.

KRAEMER, W. J.; RATAMESS, N. A. Fundamentals of Resistance Training: Progression and Exercise Prescription. Medicine and Science in Sports and Exercise, v. 36, n. 4, p. 674-688, 2004.

KUIPERS, H. et al. Variability of aerobic performance in the laboratory and its physiologic correlates. International Journal of Sports Medicine, v. 6, n. 4, p. 197-201, 1985.

MACHADO, A. G.; RIBEIRO, P. C. P. Anabolizantes e seus riscos. Adolescência e Saúde, v. 1, n. 4, p. 20-22, 2004.

MACHADO, E. P. De aprendiz a coach : [s.l.] UFRS, 2015.

MARTINS, C. M. et al. Efeitos psicológicos do abuso de anabolizantes. Ciênc. cogn., v. 5, n. 1, p. 84-91, 2005. 
MEDEIROS, M. M. M. DE. Abordagem cirúrgica para o tratamento da ginecomastia conforme sua classificação. Revista Brasileira de Cirurgia Plástica, v. 27, n. 2, p. 277-282, 2012.

NIESCHLAG, E.; VORONA, E. Doping with anabolic androgenic steroids (AAS): Adverse effects on non-reproductive organs and functions. Reviews in Endocrine and Metabolic Disorders, v. 16, n. 3, p. 199-211, 2015.

OLIVEIRA, E. S. A. Infância e cultura contemporânea: os diálogos com a mídia em contextos educativos. [s.l.] UFMT, 2014.

OLIVEIRA, L. L. DE; CAVALCANTE NETO, J. L. Sociodemographic factors, users profile and motivation to the use of anabolic steroids among young adults. Revista Brasileira de Ciencias do Esporte, v. 40, n. 3, p. 309-317, 2018.

PAULO ADRIANO SCHWINGEL. Non-medical anabolic-androgenic steroid consumption and hepatitis $\mathrm{B}$ and $\mathrm{C}$ virus infection in regular strength training practitioners. African Journal of Pharmacy and Pharmacology, v. 6, n. 22, p. 1598-1605, 2012.

PEREZ, R. R. et al. A ação do decanoato de nandrolona (Deca-durabolin $\left.{ }^{\circledR}\right)$ sobre parâmetros hematológicos e proteína total plasmática de ratos (Rattus rattus) com depressão medular induzida após administração de sulfato de vincristina (Oncovin $\left.{ }^{\circledR}\right)$. Ciência Rural, v. 35, n. 3, p. 589-595, 2005.

RIBEIRO, B. G. et al. Effects of nandrolone decanoate on the viability of muscle satellite cells during the differentiation process. Fisioterapia e Pesquisa, v. 21, n. 1, p. 16-20, 2014.

ROMER, D.; HENNESSY, M. A biosocial-affect model of adolescent sensation seeking: The role of affect evaluation and peer-group influence in adolescent drug use. Prevention Science, v. 8, n. 2, p. 89-101, 2007.

SALGADO, R. G. Em busca do corpo perfeito: as crianças na cultura da beleza e da sedução. Em aberto, v. 29, n. 95, p. 83-93, 2016.

SILVA, F. A. Body-Building e a confiança e medo no uso dos esteroides anabolizantes: uma análise sociológica. [s.l.] Universidade Federal da Paraíba, 2012.

SILVA, P. R. P. DA; DANIELSKI, R.; CZEPIELEWSKI, M. A. Esteróides anabolizantes no esporte. Revista Brasileira de Medicina do Esporte, v. 8, n. 6, p. 235-243, 2002.

TRABBOLD, V. L. M. A busca do corpo ideal como sintoma contemporâneo: os significados do corpo para os adolescentes masculinos que freqüentam academias de ginástica na cidade de Montes Claros MG. [s.l.] UFMG, 2008. 
Os significados do corpo para os adolescentes masculinos que frequentam academias de ginástica. Polêmica, v. 9, p. 89-97, 2010 